Images du travail, travail des images

4 | 2017

La relation soignants/soignés à l'épreuve de l'image

\title{
Le mal de l'œil et l'amulette : pratiques thérapeutiques en territoire purhepecha au Mexique
}

Florence Malfatto

\section{OpenEdition}

\section{Journals}

Édition électronique

URL : http://journals.openedition.org/itti/1034

DOI : 10.4000/itti. 1034

Éditeur

Université de Poitiers

Référence électronique

Florence Malfatto, « Le mal de l'œil et l'amulette : pratiques thérapeutiques en territoire purhepecha au Mexique », Images du travail, travail des images [En ligne], 4 | 2017, mis en ligne le 01 septembre 2017, consulté le 14 avril 2021. URL : http://journals.openedition.org/itti/1034 ; DOI : https://doi.org/ 10.4000/itti. 1034

Ce document a été généré automatiquement le 14 avril 2021

Images du travail, travail des images 


\section{Le mal de l'œil et l'amulette : pratiques thérapeutiques en territoire purhepecha au Mexique}

\section{Florence Malfatto}

Ail, huile et romarin : trois ingrédients employés par la Xurhiski (guérisseuse) pour prévenir le mal de l'œil.

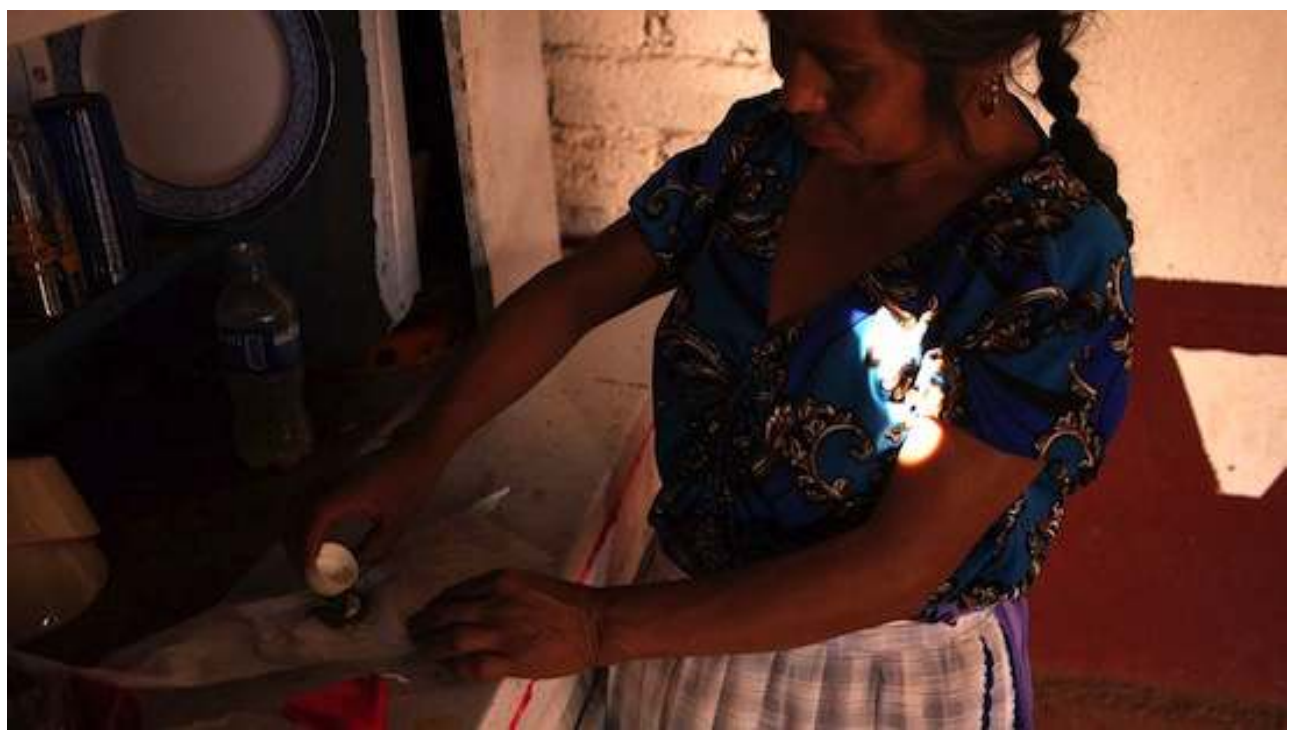

(c) Florence Malfatto, avril 2016

Cette image a été prise en avril 2016, dans la communauté purhépecha de Santa Fe de la Laguna, située dans la zone lacustre du Michoacán (centre-ouest du territoire mexicain), où je réalisais une étude filmique et ethnographique. L'objet de mon investigation portait alors sur une maladie dont plusieurs membres de la communauté estimaient que j'étais victime : le mal de ojo (littéralement, mal de l'œil). 
2 Hors-champ au moment de la prise de vue, je suis la destinataire du geste thérapeutique décrit par l'image, et me trouve donc à la fois dans une situation d'observatrice et de patiente.

3 Le personnage que l'on aperçoit au premier plan de l'image est la guérisseuse (Xurhiski) qui me soigne; elle a la connaissance des plantes et est accoucheuse. Comme de nombreuses femmes purhépecha, elle est coiffée de deux tresses et porte les boucles d'oreille caractéristiques, rondes, en or, des femmes de la région. On distingue le haut de son tablier et de sa jupe - éléments vestimentaires également constitutifs de l'identité indigène féminine.

4 La Xurhiski et moi nous trouvons dans la cuisine de la maison de cette dernière, pièce ouverte sur le patio et donnant sur la rue, par la porte d'entrée de la maison. Les murs sont en torchis. La guérisseuse se tient devant son vaisselier, meuble central autour duquel s'organisent les temps de repas qui rythment la vie des foyers purhépecha.

5 La cuisine est un espace féminin. Lors de la prise de vue, nous nous y trouvons seules. L'espace thérapeutique étant confondu avec l'espace domestique de la cuisine, les membres de la famille de la Xurhiski ont en effet pris l'habitude de s'éclipser lors de l'arrivée de patients dans la maison.

6 On aperçoit, dans l'ombre des assiettes, une bouteille dont la guérisseuse a retiré le bouchon, remplie d'un liquide qu'elle s'apprête à verser sur une gousse d'ail entourée de feuilles de romarin, disposées elles-mêmes sur quelques feuilles de papier absorbant. Cette succession de gestes, d'apparence culinaire, s'inscrit dans la phase ultime de la cure prescrite par la guérisseuse : la constitution d'une amulette de protection contre le mal de ojo.

7 Le petit sac rouge (couleur forte, particulièrement indiquée dans ce contexte thérapeutique) situé au bord cadre est en effet destiné à être garni des éléments forts ail et romarin - que la Xurhiski arrose d'huile de lys. Une fois l'amulette refermée, elle me la remettra avec ordre de la porter sur moi, en particulier si je me rends à une fête au sein du village.

8 Le mal de ojo, pathologie extrêmement répandue dans le monde purhépecha, frappe, en effet, de façon préférentielle les personnes estimées faibles ou de sang faible (enfants, étrangers, personnes à la peau claire). Elle survient dans des situations où la future victime est en contact visuel avec un groupe social étranger au sein duquel elle est amenée à s'intégrer, de façon temporaire ou durable (premières expériences de socialisation d'un enfant hors du cercle familial restreint, participation d'un étranger aux fêtes d'un village auquel il n'est pas rattaché...). La victime, ayant été scrutée fixement par de nombreux regards inconnus, contracte alors une série de symptômes, souvent cumulés: insomnie, maux de tête, maux de ventre, apathie, manifestations dépressives. Il faut alors recourir aux services d'un guérisseur ou, dans le cas où le mal est jugé trop sévère, d'un sorcier (Sikuame) - un mal de ojo prononcé pouvant faire soupçonner, en amont, l'intervention d'un sortilège.

9 Mon extériorité au monde purhépecha et mon désir de m'intégrer au groupe social faisaient de moi une victime prédisposée. Le mal me frappa à point nommé, après plusieurs semaines d'enquête sur la médecine traditionnelle purhépecha, champ auquel j'avais difficilement accès en raison du caractère confidentiel (voire secret) des pratiques thérapeutiques, largement discriminées par l'Église catholique (assimilant médecine traditionnelle et sorcellerie) et les institutions médicales publiques (les 
cliniques de villages, implantées par le gouvernement, tendent à supplanter la médecine traditionnelle).

10 Ma cure eut lieu en deux étapes. Un nettoyage rituel fut d'abord réalisé, au cours duquel la guérisseuse frotta mon corps à l'aide d'un œuf pour m'enlever le mal. Cette première étape n'ayant pas été suffisante pour fortifier mon sang, l'amulette, dans un second temps, vint renforcer l'action du nettoyage.

$11 \mathrm{Ma}$ double implication, comme cinéaste et comme malade, s'est révélée particulièrement heuristique. Prise dans le système de croyances du village, j'ai pu occuper une place privilégiée me permettant de filmer des pratiques médicales extrêmement confidentielles, tout en menant à bien une observation ethnographique au plus près du geste thérapeutique.

\section{AUTEUR}

\section{FLORENCE MALFATTO}

Florence Malfatto est doctorante en cinéma anthropologique et documentaire à l'Université Paris Ouest Nanterre La Défense. Elle travaille au moyen de l'outil filmique et s'intéresse aux processus de résistance des communautés purhépecha, au Mexique, dans les champs de la médecine et du politique. Depuis janvier 2017, elle est chargée de cours dans le département des Arts du Spectacle de Nanterre. 